\title{
REGIONAL TRENDS IN U.S. FOOD CONSUMPTION: POPULATION SCALE, COMPOSITION, AND INCOME EFFECTS
}

\author{
Patricia K. Guseman and Stephen G. Sapp*
}

Much progress has been made in the development of economic models to explain the consumption of various foods. However, the economic perspective generally neglects the position that food is fundamental both as an object of sustenance and of culture. Demographic variables such as population size, age/sex structure, and ethnic composition provide a means of accounting for sustenance and cultural differences in food consumption at both individual and aggregate levels.

Recent empirical evidence has demonstrated that demographic parameters such as age structure are more powerful explanatory referents of food consumption than is household income (Guseman and Sapp, 1983). For this reason, demand models need to reflect a broader sociodemographic framework in order to efficiently monitor food consumption trends.

The purpose of this paper is to identify regional differentials that assist in explaining the structure of demand for foods. Trends in regional consumption patterns are reviewed and projections of future food utilization on a regional basis are provided.

\section{Regional Separatism versus Massification}

Research and discussion of regional food consumption trends indicate a bifurcation of results and opinion. The first argument suggests that a massification of consumption has occurred, caused by: (1) mass communication; (2) population redistribution among regions; and (3) greater homogeneity of household incomes across regions. Researchers have suggested that mass communication acts to "standardize" consumer sentiment across the nation (Blakley). Katona (pp. 76-77) stresses the importance of social learning in mass actions regarding purchases, especially when acquisition of information is uniform. This argu-

* Research Scientist, Texas A\&M University, and Assistant Professor, Iowa State University ment implies that regional utilization of food products should become fairly similar through time.

Also, population shifts encourage a massification of food purchasing patterns. Residential movement has been substantial, especially since 1970 , with over $19,360,000$ persons relocating to a different region of the country (U.S. Bureau of the Census, 1983). This redistribution should lessen the regional variation in food intake. Northeasterners relocating to the South often begin to consume more fried chicken and Mexican food (Ryan), while maintaining prior eating habits as well. Thus, region of residence should become less salient as a determinant of food consumption.

Finally, a closure in the income gap between Southern and all other states should bring greater uniformity in consumptive behavior (Burk). This trend was observed in earlier periods, i.e. 1955 to 1965 , based on USDA's national food consumption surveys (Ecklund).

A second, and contrary argument, suggests that: (1) differential availability of commodities brings about regional variation in consumption; (2) food consumption is culturally directed by regional tastes; and (3) these preferences can be indexed by population composition variables.

Based in large part on energy availability for transportation and production, the U.S. economy has yielded increased regional specialization in the production and processing of food (Blakley, p. 69). Further, the regional correlation between population size and receipts from agricultural production lessened slightly in 1980 relative to 1970 (Guseman, Sapp and McIntosh). Thus, differential availability of agricultural commodities by region has become more pronounced.

In addition, food consumption allows for a wide variety of choice, so that regional variation in consumption may be explained by different normative patterns for specific areal units (Sanjur, pp. 250-59). Assuming that underlying cultural styles remain in the U.S., types of foods consumed and the frequency of consumption are obvious differentiating fac- 
tors. Based on this assessment, a second explanation for variation in food utilization lies with the diversity that exists in regional tastes and preferences.

Accordingly, these differences are observed through regional variations in population composition. For example, many blacks consume "soul food" whereas whites generally do not, and younger persons purchase food items not eaten by persons of advanced years (Shifflett). Compositional properties of regions, such as the proportions in various ethnic groups, as well as the age structure of the population, are thus viewed as salient dimensions directing and channeling behavior.

The two contradictory explanations will be tested through demographic analyses of food consumption patterns in the four major U.S. regions. Regional consumption trends are thus explained through evaluation of these two positions.

\section{Methodology}

As noted previously, this paper represents an attempt to discern whether differences persist in food utilization by region, to describe parameters affecting this relationship, and to offer regional projections of food consumption. Data from the Nationwide Food Consumption Survey (NFCS) for 1965-66 and 1977-78 were utilized. Additionally, projections of total population, population composition, and income by region were used to designate the effects of population shifts and economic conditions on the locational configuration of food utilization.
The NFCS surveys were undertaken by USDA, based on a stratified area probability sample of the 48 coterminous states, during the four quarters of a 12-month period. The samples include approximately 15,000 households for both 1965-66 and 1977-78, and roughly 31,000 individuals in 1977-78. This study utilizes individual intake data for 1977 , as well as household expenditures for 1965 and 1977. A four-region classification code of the NFCS data coincides with Census Bureau regions where Northeastern, North Central, Southern, and Western states are represented as the four categories. Table 1 depicts characteristics of individuals and households in the NFCS 1977-78 survey.

The projections for 1990 and 2000 include: (1) total population for the four regions, based on recently released Bureau mid-series projections (U.S. Bureau of the Census, 1983); (2) age and sex projections (U.S. Bureau of the Census, 1983) and household size and race projections for each region'; and (3) per capita personal income projections prepared for states by the Bureau of Economic Analysis (1980) and aggregated to the regional level.

\section{Findings}

Four questions were addressed in the discussion of study results, the first being whether there were significant differences in food intake by region. Table 2 shows the mean differences in food consumption by region of the country. Bonferroni T-tests (shown in Table 2), as well as general linear models, revealed

Table 1

Descriptive Characteristics of Individuals and Households in USDA National Food Consumption Survey, 1977-78, by Region

\begin{tabular}{|c|c|c|c|c|}
\hline & $\begin{array}{l}\text { Northeast } \\
\text { (n }=7,204)\end{array}$ & $\begin{array}{l}\text { North Central } \\
(\mathrm{n}=7,851)\end{array}$ & $\begin{array}{c}\text { South } \\
\text { (n }=10,738)\end{array}$ & $\begin{array}{c}\text { West } \\
\text { (n }=4,944)\end{array}$ \\
\hline \multicolumn{5}{|l|}{ Sex } \\
\hline$\%$ Male & 44.3 & 46.4 & 44.4 & 44.9 \\
\hline$\%$ Female & 55.7 & 53.6 & 55.6 & 55.1 \\
\hline Mean Age & 29.44 & 28.53 & 30.09 & 28.67 \\
\hline Household Size & 2.98 & 3.10 & 2.90 & 2.85 \\
\hline \multicolumn{5}{|l|}{ Race } \\
\hline$\%$ Black & 8.6 & 8.1 & 24.2 & 5.5 \\
\hline$\%$ Nonblack & 91.4 & 91.7 & 75.8 & 94.5 \\
\hline Per Capita & & & & \\
\hline Personal Income & $\$ 4,916$ & $\$ 4,701$ & $\$ 3,902$ & $\$ 5,219$ \\
\hline
\end{tabular}


significantly different consumption levels for eight out of nine food categories. Poultry intake did not vary substantially by region, while dairy products and fats/oils showed the greatest regional variation. The South evidenced the lowest per capita consumption for the ma- jor food categories, while Western adult respondents showed the highest levels of intake. Additionally, the South and West showed the greatest within-region variations in eating patterns.

Table 2

Mean Differences in Food Consumption (Grams per day) of U.S. Regions: 1977-78 (Respondents 18 Years and Older)

\begin{tabular}{|c|c|c|c|c|c|c|c|c|c|}
\hline \multicolumn{10}{|c|}{ Major Food Categories } \\
\hline $\begin{array}{l}\text { Regional } \\
\text { Comparisons }\end{array}$ & $\begin{array}{c}\text { Cereals/ } \\
\text { Bakery } \\
\text { Items } \\
(n=13,710) \\
\end{array}$ & $\begin{array}{l}\text { Fresh } \\
\text { Fruit } \\
(n=9,619)\end{array}$ & $\begin{array}{c}\text { Fresh } \\
\text { Vegetables } \\
(n=14,085)\end{array}$ & $\begin{array}{c}\text { Fats and } \\
\text { Oils } \\
\text { (n=14,462) }\end{array}$ & $(n=11,893)$ & $(n=9,040)$ & Poultry & $(n=4,487)$ & $\begin{array}{c}\text { Dairy } \\
\text { Products } \\
\text { (n=16,475) }\end{array}$ \\
\hline \multicolumn{10}{|l|}{ Northeast } \\
\hline North Central & $19.8^{\text {*a }}$ & 2.5 & $26.4^{*}$ & -0.3 & -5.2 & -1.5 & -1.2 & $15.7^{*}$ & $-91.2 *$ \\
\hline South & $-34.9 *$ & $51.5^{*}$ & 8.0 & $11.9 *$ & 2.2 & $21.8^{*}$ & -3.9 & -1.1 & 57.8* \\
\hline West & 1.6 & $-57.0^{*}$ & -8.3 & $-11.6^{*}$ & $-21.4^{*}$ & $20.9^{*}$ & -6.8 & $19.4^{*}$ & $-154.2^{*}$ \\
\hline \multicolumn{10}{|l|}{ North Central } \\
\hline Northeast & $-19.8^{*}$ & -2.5 & $-26.4^{*}$ & 0.3 & 5.2 & 1.5 & 1.2 & $-15.7^{*}$ & $91.2^{*}$ \\
\hline South & $-54.8^{*}$ & $49.0^{*}$ & $-18.4^{*}$ & $12.3^{*}$ & 7.3 & $23.3^{*}$ & -2.7 & $-15.8^{*}$ & $149.0^{*}$ \\
\hline West & -18.2 & $-59.5^{*}$ & $-34.6^{*}$ & $-11.3^{*}$ & $-16.3^{*}$ & $22.4^{*}$ & -5.5 & 3.7 & $63.0^{*}$ \\
\hline \multicolumn{10}{|l|}{ South } \\
\hline Northeast & $34.9^{*}$ & $-51.5^{*}$ & -8.0 & -11.9 & -2.2 & $-21.8^{*}$ & 3.9 & 1.1 & $57.8^{*}$ \\
\hline North Central & $54.8^{*}$ & $-49.0^{*}$ & $18.4^{*}$ & $-12.3^{*}$ & -7.3 & $-23.3^{*}$ & 2.7 & $15.8^{*}$ & $-149.0^{*}$ \\
\hline West & $36.6^{*}$ & -108.5 & $-16.2^{*}$ & $-23.6^{*}$ & $-23.6^{*}$ & -9.1 & -2.8 & $19.5^{*}$ & $-212.1 *$ \\
\hline \multicolumn{10}{|l|}{ West } \\
\hline Northeast & -1.6 & $57.0^{*}$ & 8.3 & $11.6^{*}$ & $21.4^{*}$ & $-20.9 *$ & 6.8 & $-19.4^{*}$ & $154.2 *$ \\
\hline North Central & 18.2 & $59.5^{*}$ & $34.6^{*}$ & $11.3^{*}$ & $16.2^{*}$ & -22.4 & 5.5 & -3.7 & $63.0^{*}$ \\
\hline South & $-36.6^{*}$ & $108.5^{*}$ & $16.2^{*}$ & $23.6^{*}$ & $23.6^{*}$ & 9.1 & 2.8 & $-19.5^{*}$ & $212.1^{*}$ \\
\hline
\end{tabular}

aThe Bonferroni (Dunn) T-test was used for the purpose of paired comparisons. Regions that were significantly different at the .05 level are signified by an asterisk(*). 
Table 3

The Mean, Range, Standard Deviation, and Coefficient of Variation for Household Consumption Expenditure Relationships for Foods for 1965-66 and 1977-78 Across Regions ${ }^{\mathrm{a}}$

\begin{tabular}{|c|c|c|c|c|c|c|c|c|c|}
\hline \multirow[b]{2}{*}{ Food } & \multicolumn{4}{|c|}{$1965-66$} & \multicolumn{4}{|c|}{$1977-78$} & \multirow{2}{*}{$\begin{array}{c}\text { Percent Change } \\
\text { in Coefficient } \\
\text { of Variation } \\
1977-1965\end{array}$} \\
\hline & Mean & Range & $\begin{array}{l}\text { Standard } \\
\text { Deviation }\end{array}$ & $\begin{array}{l}\text { Coefficient } \\
\text { of Variation }\end{array}$ & Mean & Range & $\begin{array}{l}\text { Standard } \\
\text { Deviation }\end{array}$ & $\begin{array}{c}\text { Coefficient } \\
\text { of Variation }\end{array}$ & \\
\hline $\begin{array}{l}\text { Cereals/ } \\
\text { Bakery Items } \\
\text { Fresh }\end{array}$ & 131.5 & 29.1 & 13.0 & 9.9 & 82.6 & 17.5 & 7.4 & 9.0 & -9.5 \\
\hline $\begin{array}{l}\text { Fruit } \\
\text { Fresh }\end{array}$ & 35.9 & 18.9 & 8.5 & 23.6 & 35.9 & 22.5 & 9.9 & 27.6 & 16.9 \\
\hline $\begin{array}{l}\text { Vegetables } \\
\text { Fats and }\end{array}$ & 33.3 & 13.5 & 5.5 & 16.6 & 31.4 & 17.1 & 7.2 & 23.1 & 38.8 \\
\hline Oils & 8.3 & 3.7 & 1.7 & 20.5 & 4.9 & 1.5 & 0.7 & 14.5 & -29.5 \\
\hline Beef & 70.7 & 25.5 & 12.0 & 17.0 & 64.2 & 7.3 & 4.1 & 6.4 & -62.5 \\
\hline Pork & 26.2 & 12.8 & 6.7 & 25.6 & 19.3 & 14.3 & 6.5 & 33.8 & 32.1 \\
\hline Poultry & 9.6 & 3.0 & 1.4 & 14.2 & 9.6 & 6.3 & 2.9 & 30.6 & 116.2 \\
\hline Fish & 2.8 & 2.6 & 1.4 & 40.3 & 3.5 & 2.1 & 1.2 & 32.2 & -20.1 \\
\hline Dairy Products & 156.4 & 18.1 & 8.2 & 5.3 & 252.0 & 66.1 & 28.3 & 11.2 & 113.2 \\
\hline
\end{tabular}

The means, ranges, standard deviations, and coefficients of variation were obtained across the four major U.S. regions by dividing quantity consumed (measured in grams per day for the Spring) for each food by total food intake and multiplying by the expenditures per food product relative to total food expenditures, i.e. $\left(Q_{i} / Q_{t}\right) *\left(E_{i} / E_{t}\right) *$ $(1,000)$.

A second portion of the analysis assesses whether these regional differences are becoming more intensified through time. Table 3 presents the variation across the four regions for both 1965 and 1977, controlling in each case for relative expenditures. The final column shows the change in regional variation over the measurement period for each food category.

Comparisons of proportions of household consumption for broad food groups suggests that consumption has not become homogeneous across regions (Table 3). Levels of consumption varied more by region in 1977 relative to 1965 for dairy products, some nonpreferred meats, and vegetables and fruits. On the other hand, regional variation had lessened for an equivalent number of foods, including some processed foods, such as cereals, baked goods and sweets, and preferred meats.

No consistent "massification" or homogeneity of eating habits has occurred, despite forces leading to this pattern. Regional differences that continue to exist may result from compositional differences or income variation, although Table 3 provides some control for the latter with the inclusion of product expenditures per quantity consumed.

A third portion of the analysis required decomposing various demographic and economic effects on food consumption for the four regions. General linear models explaining individual commodity consumption were developed, based on the 1977-78 NFCS data. Input variables were per capita personal income, and a log inverse measure of personal income, as well as mean age, sex, household size and race. In each case, projections were included on a regional basis for each variable for the years 1990 and 2000 . Consumption of dairy and of beef products represent the dependent variables for the following examples.

Dairy intake was used as an example because of the increase in regional variation displayed ov'sr a 12 year period (Table 3). Also, Table 2 pointed to highly significant differences in average intakes for dairy products by region. Finally, coefficients of determination for the nine commodities revealed that dairy consumption could be more aptly explained by income and compositional variables than the other commodities, so that fewer exogeneous influences existed in the case of dairy intake.

Beef consumption was utilized as the second commodity of interest because of the contrast provided with dairy intake. Beef consumption has traditionally been highly income elastic and shows a high positive correlation with income, unlike dairy products. Additionally, beef consumption has become more standardized across regions, as shown in Table 3, unlike 
dairy items which show a greater regional specialization over time. Finally, beef intake in 1977-78 varied for only the West, while the remaining regions evidenced similar consumption patterns.

Regional consumption (based on average daily intake) for dairy and beef products is represented by:

$$
\begin{aligned}
& \mathrm{C}=\beta_{0 \mathrm{r}}+\beta_{1 \mathrm{r}}(\mathrm{Y})+\beta_{2 \mathrm{r}}(\log \mathrm{Y})^{-1}+\beta_{\mathrm{sr}}(\mathrm{A})+ \\
& \beta_{4 \mathrm{r}}(\mathrm{H})+\left[\sum_{\mathrm{i}=1}^{2} \lambda_{\mathrm{r}} \mathrm{S}_{\mathrm{r}}\right]+\left[\sum_{\mathrm{i}=1}^{2} \mathrm{~K}_{\mathrm{r}} \mathrm{R}_{\mathrm{r}}\right]+\mathrm{U}_{\mathrm{r}}
\end{aligned}
$$

The subscript " $r$ " refers to the region and the variables are:

$\mathrm{C}=$ average daily intake (in grams)

$\mathrm{Y}=$ annualized per capita personal income

$A=$ age of individual $(0-100)$

$\mathrm{H}=$ household size

$\mathrm{S}=$ dummy indicating sex of individual

$\mathbf{R}=$ dummy indicating race (black and nonblack) of individual

$\mathrm{U}=$ stochastic residual

General linear models for the four regions detailing relationships between the independent variables for dairy and beef consumption showed age, followed by sex, race, per capita personal income, and household size as having the greatest explanatory power. ${ }^{2}$ The $\log$ inverse of income was not significant in several cases. This variable was included to handle saturation effects in the projections of dairy and beef consumption, as these models provide the basis for projections of consumption by region.
In the analysis, change in regional demand for products assumes fixed prices, constant levels of availability and no change in consumer sentiment regarding foods. With these assumptions, the Figure 1 diagram is used to explain alterations in the structure of demand for foods, with dairy and beef products as examples. Aggregate demographic effects are dependent on changes in total population for each region, as well as changes in composition. These two categories are not mutually exclusive; for example, alterations in composition account for changes in total population, in that fertility and mortality rates and the concomitant age structure directly affect population scale. Total structural effects are viewed through compositional changes in the population as well as household economic conditions. Again, these two dimensions are highly interrelated, with aggregate income dependent on the proportion in income-earning ages and on the gender, racial and educational breakdown of the population by region. For this analysis, then, changes in consumption are driven by changes in total demographic and structural components of the population.

Table 4 presents illustrative projections of consumption of dairy and beef products, based on projected regional changes in income, age, sex, household size and race. Aggregate, as well as per capita, consumption levels are included, to show the effects of population growth and decline for the four regions.

Aggregate dairy consumption was projected to decline in all cases except the South (in 2000), despite projected population increases

Table 4

Illustrative Projections of Dairy and Beef Consumption,

\begin{tabular}{|c|c|c|c|c|c|c|c|c|}
\hline & \multicolumn{3}{|c|}{$\begin{array}{l}\text { Per Capita } \\
\text { Consumption }\end{array}$} & \multicolumn{3}{|c|}{$\begin{array}{l}\text { Aggregate Consumption } \\
\text { (in thousands) }\end{array}$} & \multicolumn{2}{|c|}{$\begin{array}{l}\text { Percent Change in } \\
\text { Aggregate Intake }\end{array}$} \\
\hline & 1977 & $1990 *$ & $2000^{*}$ & 1977 & $1990 *$ & $2000^{*}$ & $1977-1990$ & $1977-2000$ \\
\hline \multicolumn{9}{|l|}{ DAIRY } \\
\hline $\begin{array}{l}\text { Northeast } \\
\text { North Central } \\
\text { South } \\
\text { West }\end{array}$ & $\begin{array}{r}1,046 \\
1,077 \\
836 \\
1,111\end{array}$ & $\begin{array}{l}551 \\
576 \\
657 \\
605\end{array}$ & $\begin{array}{l}498 \\
543 \\
617 \\
561\end{array}$ & $\begin{array}{l}51,396,988 \\
62,792,331 \\
60,059,076 \\
45,896,521\end{array}$ & $\begin{array}{r}26,686,748 \\
34,712,870 \\
57,549,389 \\
32,016,721\end{array}$ & $\begin{array}{l}23,107,499 \\
32,424,702 \\
60,976,753 \\
35,073,271\end{array}$ & \begin{tabular}{r|}
-48.1 \\
-44.7 \\
-4.2 \\
-30.2
\end{tabular} & $\begin{array}{r}-55.0 \\
-48.4 \\
+1.5 \\
-23.6\end{array}$ \\
\hline \multicolumn{9}{|l|}{ BEEF } \\
\hline $\begin{array}{l}\text { Northeast } \\
\text { North Central } \\
\text { South } \\
\text { West }\end{array}$ & $\begin{array}{l}138 \\
144 \\
131 \\
154\end{array}$ & $\begin{array}{l}171 \\
143 \\
148 \\
176\end{array}$ & $\begin{array}{l}176 \\
154 \\
165 \\
186\end{array}$ & $\begin{array}{l}6,780,865 \\
8,395,632 \\
9,411,171 \\
6,361,894\end{array}$ & $\begin{array}{r}8,282,094 \\
8,617,952 \\
12,963,942 \\
9,313,955\end{array}$ & $\begin{array}{r}8,166,506 \\
9,195,956 \\
16,306,587 \\
11,628,571\end{array}$ & $\begin{array}{r}+22.1 \\
+2.6 \\
+37.7 \\
+46.4\end{array}$ & $\begin{array}{r}+20.4 \\
+9.5 \\
+73.3 \\
+82.8\end{array}$ \\
\hline
\end{tabular}
1977 to 2000, by U.S. Regions (in grams)

*Assumes per capita income growth. 
Regional Trends in U.S. Food Consumption:

Population Scale, Composition, and Income Effects

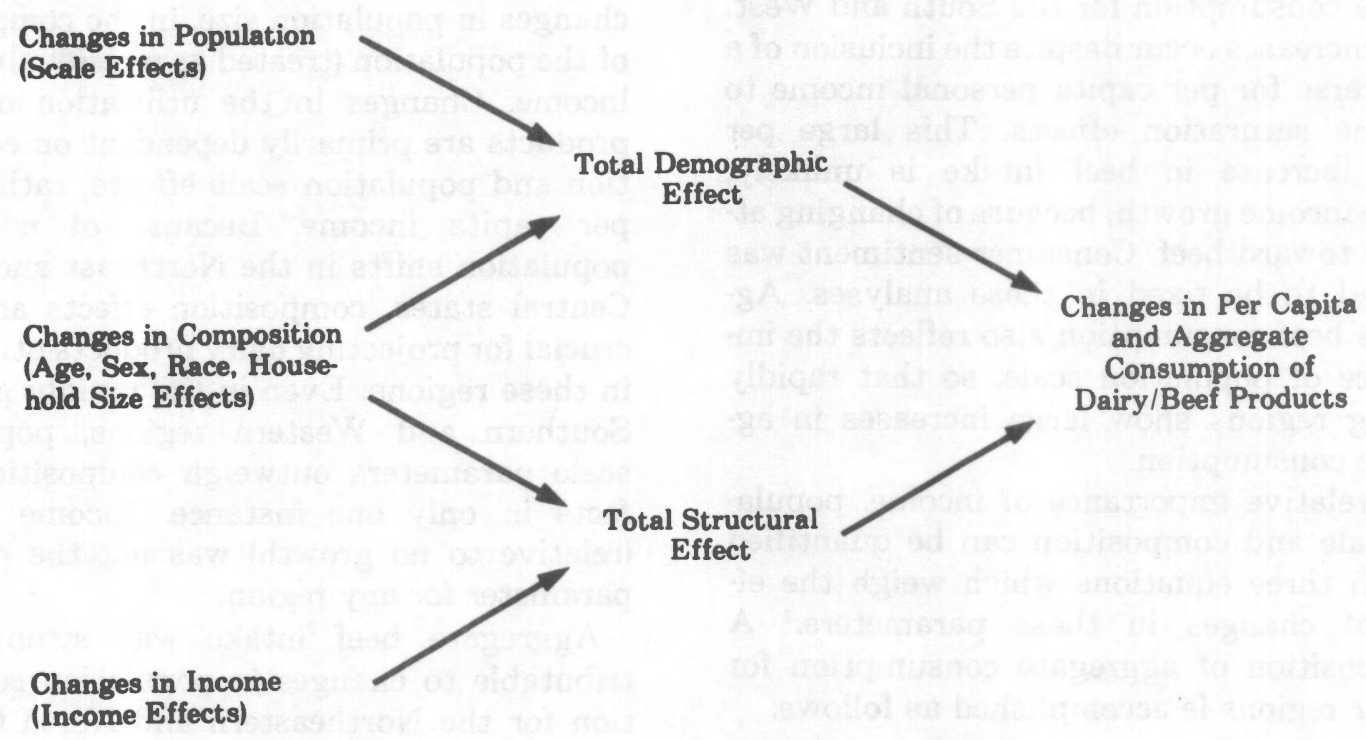

Figure 1

Changes in the Regional Structure of Demand for Dairy/Beef Products*

-This model assumes fixed relative prices, constant levels of availability across regions, and no change in consumer sentiment regarding dairy/beef products. 
for both the South and West (Table 4). All four regions also showed a decrease in per capita intake. Consumption of dairy products typically falls with the growth of per capita income. Further, the aging of the population and other compositional changes lead to a projected decline in both individual and aggregate consumption.

Illustrative projections for beef consumption show large increases in per capita and aggregate consumption for the South and West. These increases occur despite the inclusion of a log inverse for per capita personal income to subsume saturation effects. This large per capita increase in beef intake is unlikely, despite income growth, because of changing attitudes toward beef. Consumer sentiment was assumed to be fixed in these analyses. Aggregate beef consumption also reflects the importance of population scale, so that rapidly growing regions show large increases in aggregate consumption.

The relative importance of income, population scale and composition can be quantified through three equations which weigh the effects of changes in these parameters. ${ }^{3}$ A decomposition of aggregate consumption for the four regions is accomplished as follows:

I. Scale Effects (SE):

$$
\frac{C_{0}\left[\left(P_{1} / P_{0}\right)-1\right]}{C_{1 Y}-C_{0}}
$$

II. Composition Effects (CE):

$$
\frac{\mathrm{C}_{1}-\left[\mathrm{C}_{0}\left(\mathrm{P}_{1} / \mathrm{P}_{0}\right)\right]}{\mathrm{C}_{1 \mathrm{Y}}-\mathrm{C}_{0}}
$$

III. Income Effects (IE):

$$
\frac{C_{1 Y}-C_{1}}{C_{1 Y}-C_{0}}
$$

where:

$\mathrm{P}_{0}=$ population at base period

$\mathrm{P}_{1}=$ population at estimate period

$\mathrm{C}_{0}=$ consumption at base period

$\mathrm{C}_{1}=$ consumption at estimate period with no income growth

$\mathrm{C}_{1 \mathrm{Y}}=$ consumption at estimate period with income growth

Then, $\mathrm{SE}+\mathrm{CE}+\mathrm{IE}=1.0$;

$\mathrm{SE}+\mathrm{CE}=$ share of total change in consumption $\left(\mathrm{C}_{1}-\mathrm{C}_{0}\right)$ attributable to demographic factors; and

$\mathrm{CE}+\mathrm{IE}=$ share of change in consumption $\left(C_{1}-C_{0}\right)$ attributable to structural factors.

Income is viewed as the most volatile structural variable and is the only component which is manipulated in the above three equations, with both an income growth and a no growth scenario utilized.

Table 5 depicts the relative importance of changes in population size, in the composition of the population (treated as a residual), and in income. Changes in the utilization of dairy products are primarily dependent on composition and population scale effects, rather than per capita income. Because of negligible population shifts in the Northeast and North Central states, composition effects are more crucial for projecting dairy products utilization in these regions. Even in the rapidly growing Southern and Western regions, population scale parameters outweigh compositional effects in only one instance. Income growth (relative to no growth) was not the primary parameter for any region.

Aggregate beef intake was strongly attributable to changes in population composition for the Northeastern and North Central states in 1990 and for the Northeastern states again in 2000 . However, the South consistently revealed the importance of per capita income growth, as did the North Central states in 2000 , based on these illustrative projections. Population scale affected beef consumption more than did other factors in the Western states.

Table 5 also provides a "total demographic effect," representing both scale and compositional components of change. While the three effects of scale, composition, and income must sum to 1.0 , there are no maximum or minimum values for examining the total demographic effect. Likewise, a "total structural effect" combines the influences of composition and income components, and also has no maximum or minimum value.

The largest total demographic effects were registered for beef products in the North Central and Western regions of the nation for both 1990 and 2000. Thus, the impact of population growth, as well as the aging of the population and other compositional changes provide a strong demographic force precipitating both 
Table 5

Isolation of Population Scale

Composition and Income Effects

for Consumption of Dairy and Beef Products

\begin{tabular}{|c|c|c|c|c|c|}
\hline & & ve Change in & umption & & \\
\hline & & & & Total & Total \\
\hline & $\begin{array}{l}\text { Scale } \\
\text { Effects }\end{array}$ & $\begin{array}{l}\text { Composition } \\
\text { Effects }\end{array}$ & $\begin{array}{l}\text { Income } \\
\text { Effects }\end{array}$ & $\begin{array}{l}\text { Effect } \\
\text { (SE + CE) }\end{array}$ & $\begin{array}{l}\text { Effect } \\
\text { (CE + IE) }\end{array}$ \\
\hline Dairy: 1990 & & & & & \\
\hline Northeast & 0.04 & $\underline{0.87}$ & 0.09 & 0.91 & 0.96 \\
\hline North Central & -0.07 & 1.04 & 0.04 & 0.96 & 1.07 \\
\hline South & -1.02 & 1.80 & 0.23 & 0.78 & 2.03 \\
\hline West & -0.74 & $\overline{1.62}$ & 0.13 & 0.87 & 1.74 \\
\hline Dairy: 2000 & & & & & \\
\hline Northeast & -0.11 & $\underline{0.77}$ & 0.12 & 0.88 & 0.89 \\
\hline North Central & -0.05 & 1.00 & 0.05 & 0.95 & 1.05 \\
\hline South & -1.45 & 2.66 & -0.21 & 1.21 & 2.45 \\
\hline West & -1.80 & $\overline{2.51}$ & 0.29 & 0.71 & 2.80 \\
\hline Beef: 1990 & & & & & \\
\hline Northeast & -0.08 & $\underline{0.75}$ & $\underline{0.33}$ & 0.66 & 1.08 \\
\hline North Central & 1.46 & $-\overline{7.40}$ & $\overline{6.94}$ & -5.94 & -0.46 \\
\hline South & $\overline{0.57}$ & -0.33 & $\underline{0.75}$ & 0.24 & 0.43 \\
\hline West & $\underline{0.57}$ & $\overline{0.08}$ & $\overline{0.35}$ & 0.65 & 0.43 \\
\hline Beef: 2000 & & & & & \\
\hline Northeast & -0.29 & $\underline{0.79}$ & 0.50 & 0.49 & 1.29 \\
\hline North Central & 0.25 & $-\overline{1.68}$ & 2.43 & -1.43 & 0.75 \\
\hline South & 0.51 & -0.19 & $\overline{0.67}$ & 0.33 & 0.48 \\
\hline West & $\underline{0.60}$ & 0.04 & 0.36 & 0.64 & 0.40 \\
\hline
\end{tabular}

*Underlining represents most powerful effect in the decomposition. Scale, composition and income effects sum to one.

increases (in the West) and decreases (in the North Central region) in beef consumption. On the other hand, population scale and composition parameters tended to cancel each other out for dairy consumption in both 1990 and 2000 , so that a strong structural effect was shown.

\section{Discussion}

Population redistribution and other trends have not substantially "standardized" food consumption behavior across regions of the United States. Controlling for regional variation in food prices, the utilization of commodities has become less uniform among regions for beef, fats and oils, fish and cereal/bakery items. At the same time, a trend toward greater homogeneity of consumption is evidenced for poultry, dairy products, fresh vegetables and fruits, and pork. Population shifts, mass communications, and a lessening of the income gap across regions may encourage the massification of food habits in the long term, but recent NFCS surveys show that region of residence remains a strong determinant of differential food consumption.

As has been noted, beef-more than any other major food commodity -is highly income elastic. This sensitivity was revealed in the decomposition of projected aggregate consumption. On the other hand, dairy consumption was driven primarily by population composition parameters, which explain at least 50 percent of the total effect for all four regions in both 1990 and 2000.

The population scale parameter can be readily visualized, while the composition effect represents a composite of the changes occurring in the age/sex structure, racial propor- 
tions, and household size. Further analysis, depicting parameters as change variables, can clearly isolate the transformations in consumption brought about by each compositional change.

Earlier studies of household expenditures (Haidacher, et al., pp. 96-132; Raunikar, Purcell and Ford, pp. 19-22) showed the importance of regional location in estimating the demand for food commodities. Clearly, these illustrative projections of dairy and beef utilization portray the salience of regional characteristics, both demographic and economic, in monitoring food consumption trends. Spatial aspects of consumer demand are important to all segments of the food industry-from producers to distributers and retailers. Producers need information with respect to potential market demand by location and size of markets. The processing and distributing industries rely on such information for efficiencies in plant location and the distribution of packaged foods. The spatial and temporal aspects of food consumption require continuous evaluation on a regional level. However, a void has existed in the inclusion of population parameters to estimate regional consumption trends. The results of this study provide a basis for assessing regional food utilization patterns and for decomposing the demographic, as well as economic, effects of changing consumption behavior.

\section{FOOTNOTES}

${ }^{1}$ Household size and race projections were independently derived. Household size trends for $1970-1980$ on a state basis were extrapolated to 1990 and 2000 with a correction factor applied from household size Series $A$, population Series I (U.S. Bureau of the Census, 1979: p. 17). This approach to projecting household size was used after testing two other alternatives. Projections of racial composition on a state basis were undertaken with an arithmetic trending. Other approaches included an exponential and logarithmic trending of racial composition.

${ }^{2}$ Coefficients and significance levels for variables in each of the four models are available upon request. Adjusted coefficients of determination ranged from 0.05 for beef in the Northeast and the South to 0.20 for dairy products in the Northeast.

'Expenditures within major economic sectors have been subjected to a similar decomposition analysis (Musgrove, pp. 18-21).

\section{REFERENCES}

Blakley, Leo V. 1981. "Regional Markets for Agricultural and Food Products: Needed Research." Southern Jour nal of Agricultural Economics (July): 69-77.

Burk, Marguerite C. 1961. Influences of Economic and Social Factors on U.S. Food Consumption. Washington, D.C.: U.S. Government Printing Office. Economic Research Service, USDA.

Guseman, Patricia K. and Stephen G. Sapp. 1983. "Demographic Trends and Consumer Demand for Agricultural Products." Southern Rural Sociology 1 (September): 1-24.

Guseman, Patricia K., Stephen G. Sapp, and Wm. Alex McIntsosh. 1983. "Cultural Components in Consumer Demand for Agricultural Products." Paper presented at the Rural Sociological Association meetings, Lexington, Kentucky, August.

Haidacher, Richard C., John A. Craven, Kuo S. Huang, David M. Smallwood, and James R. Blaylock. 1982. Consumer Demand for Red Meats, Poultry, and Fish. Washington, D.C.: U.S. Department of Agriculture, Economic Research Service Report No. 820818.

Katona, George. 1960. The Powerful Consumer. New York: McGraw-Hill.

Musgrove, Phillip. 1982. U.S. Household Consumption, Income, and Demographic Changes. Washington, D.C.: Resources for the Future.

Ryan, Cecil, 1980. Unpublished communication. Texas A\&M University, College Station, Texas, November.

Sanjur, Diva. 1982. Social and Cultural Perspectives in Nutrition. Englewood Cliffs, N.J.: Prentice-Hall.

Sapp, Stephen G. and Patricia K. Guseman. 1984. "Demand Forecasting During Periods of Rapid Social Change: The Case of Beef Demand." Paper presented at the Rural Sociological Society meetings, College Station, Texas, August.

Shifflett, Peggy Ann. 1980. "Future Time Perspective and Food Habits of the Aged." An unpublished doctoral dissertation. College Station, Texas: Texas A\&M University, Department of Sociology.

U.S. Bureau of the Census. 1983. Provisional Projections of the Population of States, by Age and Sex: 1980 to 2000. Washington, D.C.: U.S. Government Printing Office, Current Population Reports, Population Estimates and Projections Series P-25, No. 937.

U.S. Bureau of the Census. 1979. Projections of the Number of Households and Families: 1979 to 1995. Washington, D.C.: U.S. Government Printing Office, Current Population Reports, Population Estimates and Projections Series D-25, No. 805. 